\title{
GÖLYAKA İLÇESİNDE (DÜZCE) YEREL HALK TARAFINDAN KULLANILAN BİTKILERİN YÖRESEL İSİMLERİ
}

\author{
Ayla KÖYSAL ${ }^{1}$ ve Enaz ALTUNDAĞ ÇAKIR ${ }^{2}$ \\ 1) Düzce İl Tarım Orman Müdürlüğü, Düzce 0000-0003-2336-2293, ileti: aylakoysal@gmail.com \\ 2) Düzce Üniversitesi, Fen Edebiyat Fakültesi, Biyoloji Bölümü, Düzce \\ 0000-0002-7290-8582: ileti: ernazaltundag@duzce.edu.tr
}

\begin{abstract}
Özet
İnsanoğlu ilkçağlardan günümüze kadar yaşadığ1 bölgede çevresindeki bitkilerden değişik amaçlarla yararlanmış, bu bitkileri çeșitli isimlerle adlandırarak bu adların kuşaklar boyunca nesilden nesile aktarılmasını sağlamıştır. Ülkemiz sahip olduğu bitki çeşitliliği, farklı coğrafik ve iklimsel özellikleri bakımından dünyanın en zengin bitki örtüsüne sahip ülkelerin başında gelmektedir. Çeşitli medeniyetlere ev sahipliği yapan Anadolu bu bitkilerden yararlanma bakımından oldukça zengin bir kültüre de ev sahipliği yapmaktadır. Ülkemizde var olan bu bitkilerin farklı yörelerde çeşitli isimler ile adlandırılması kültürel bir zenginlik olup, bu zenginliğin yapılan bilimsel çalışmalarla kayıt altına alınması büyük önem arz etmektedir. Bu çalşsma Düzce'nin Gölyaka ilçesinde yöre halkı tarafından çeşitli amaçlarla kullanılan bitkilerin yöresel ve bilimsel adlarının belirlenmesi amacı ile yapılmışıtı. Arazi çalışmaları 20192020 yılları arasındaki farklı vejetasyon tarihlerini kapsayan bu çalışmada Gölyaka ilçesine bağlı 10 köy araştırma bölgesi olarak seçilmiștir. Bu kapsamda yörede yașayan halkın gıda, tıbbi, süs, hayvan yemi, yakacak ve boyama amaçlı olarak kullandığı yabani ve kültür bitkilerinin yöresel ve bilimsel isimlerinin kayıt altına alınması hedeflenmiştir. Yapılan araştırma sonucunda 44 familyaya ait 114 takson belirlenmiştir. Gölyaka'da teşhisi yapılan bitkiler için 189 farklı yöresel ismin kullanıldığı, bu bitkilerin geleneksel adlandırılmasında en yaygın kullanılan yaklaşımın renk özelliklerinden yararlanılarak olduğu belirlenmiştir.
\end{abstract}

Anahtar Kelimeler; Düzce, Gölyaka, Doğal Bitkiler, Yöresel İsim

LOCAL NAMES OF PLANTS WHICH HAVE FOLK USAGE IN GOLYAKA DISTRICT (DÜZCE)

\section{Abstract}

The humankind has benefited from the plants around it for different purposes from ancient times until today and, by referring these plants with various names ensured. Our country is one of the countries with the richest vegetation in the world in terms of plant diversity, different geographical and climatic features. Anatolia, which has hosted various civilizations, is also home to a very rich culture in terms of benefiting from these plants. It is a cultural richness that these plants are referred with different names in different regions of our country, and it is of great importance to keep the record of this richness with scientific studies. This study was conducted for the aim of determining the local and scientific names of the plants used by locals in Gölyaka district of Düzce for various purposes. In this study, whose field works cover different vegetative dates between 2019 and 2020, 10 villages of Gölyaka district were selected as research areas. In this context, it is aimed to record the local and scientific names of the plants used by the people living in the region for food, medicinal, handicraft, fodder, firewood and dye purposes. As a result of the research, 114 taxa belonging to 44 families were determined. It has been recorded that 189 different local names are being used in Gölyaka, and the most commonly used approach in the traditional naming of these plants is using the color features.

Keywords; Düzce, Gölyaka, Natural Plants, Local Name. 


\section{Giriş}

İnsanoğlu ilkçağlardan günümüze kadar yaşadığı bölgedeki bitkilerden öncelikli olarak besin kaynağ1 ve sağlık problemlerinde kullanmak üzere çok farklı amaçlarla yararlanmıştır. Hangi bitkilerin şifalı hangilerinin zehirli olduğu bilgisini deneme yanılma yoluyla edinen insanoğlu bu bilgileri nesiller boyunca aktarmıştır (Yeşil ve Akalın, 2010:90-91; Dikilitaş ve ark., 2016:253). Çevresindeki bitkilerden çeşitli amaçlarla yararlanan Anadolu'da halk gıda, ilaç ve boyar madde olarak kullanılan, aynı zamanda güzel kokulu veya zehirli olan bitkileri edindikleri tecrübelerle tanımakta ve bunlara özel adlar vermektedir. Türkçe bitki adları ile ilgili ilk bilgiler 11. yüzyılda Kaşgarlı Mahmut tarafindan yazılmış olan "Dîvânu Lugâti't-Türk" te yer almaktadır. $\mathrm{Bu}$ kitapta yer alan Türkçe bitki adlarının birçoğu günümüzde Anadolu'da yaygın olarak kullanılmaktadır. Yurdumuzun bitki çeşitliliği ile ilgili "Abide Eser" olarak kabul edilen "Flora Orientalis" adlı eserde Anadolu bitkilerin bilimsel adlarının yanı sıra 20 kadar bitki türünün Türkçe yöresel adı kayıtlıdır (Baytop, 2007).

Türkiye'de bitkilere yöresel ad verilmesinde, bitkinin kullanılışı, morfolojik özellikleri veya yetişme ortamının dikkate alındığı anlaşılmaktadır. Aynı zamanda ayı soğanı, domuz pıtrağı, deve kulağı, eşek dikeni, kurt boğan, it burnu gibi hayvan adlar1 da bitki adlandırılmasında yaygın kullanılmıştır (Baytop, 2007). Bitkilerin yöresel isimlerinin ve kullanımlarının ülkeden ülkeye, ilden ile, köyden köye ve hatta aynı köyün insanları arasında bile çok çeşitlilik gösterdiği yöresel isim çeşitliliğinden anlaşılmaktadır (Yıldırımlı, 2004:176). Gerek Anadolu ağızlarında, gerekse yazı dilimizde bitki adlarının önemli bir yeri vardır. Bitki adlarının önemli bir yer tutmasında Türk insanının doğayla iç içe yaşaması, tarım ve hayvancılıkla uğraşmas1, ekip biçtĭgi toprağ1 "sadık bir yâr" olarak görmesi gibi faktörler etkili olmuştur (Alkayış, 2019).

Etnobotanik insanlarla bitkiler arasındaki ilişkileri inceler (Ertuğ, 2004:181). Etnobotanik çalışmalar ile insanlarla bitkilerin milyonlarca yıldan beri devam eden karş1lıkl etkileşimleri incelenerek, bu bitkilerin hangi amaçlarla ve nasıl kullanıldıklarının araştırılmasının yanı sıra bu bitkilere verilen yöresel adları da kayıt altına alınmaktadır (Altundağ ve Özhatay 2009:104-114; Sevgi ve ark., 2018:36).

Araştırma sahası olarak seçilen Gölyaka ilçesi, Marmara bölgesi ile Karadeniz bölgesi arasında yer alarak geçiş güzergâhı üzerinde bulunan Düzce iline bağlıdır. Gölyaka ilçesi iklim ve habitat özellikleri ile oldukça zengin bir flora ve vejetasyona sahip olmasının yanı sira zengin bir kültürel çeşitliliği de içermektedir (Aksoy ve ark., 2015:409-410). Yapılan bu çalşsma ile Düzce ili Gölyaka ilçesinde geleneksel kullanımı olan bitkilerin yöresel adları kayıt altına alınmıştır.

\section{Yöntem}

Araştırmanın yapıldığı Gölyaka ilçesi, yurdumuzun Karadeniz Bölgesi'nde Düzce sinırları içerisinde yer almaktadır. Düzce ilinin batı ucunda yer alan Gölyaka ilçesinin yüzölçümü 219,983 km²'dir. Gölyaka ilçesinde iklim olarak, tipik Karadeniz iklimi gözlenir. Geleneksel kullanıma sahip bitki örneklerinin yöresel isimlerini kayıt etmek amacıyla 2019-2020 yıllar1 arasindaki farklı vejetasyon dönemlerinde Haciyakup, Aksu, Zekeriya, Sarıdere, Kuyudüzü, Yenimahalle, Saçmalipınar, Yunusefendi, Hamamüstü ve Bakacak köylerine ziyaretler yapılmıştır. Bu köylerin seçiminde ilçenin florasını ve kültürel çeşitliliğini yansıtması açısından farklı habitatta bulunan köylerin seçilmesine dikkat edilmiştir. Bitki örneklerinin toplandığı köylerin haritadaki yerleri Şekil 1' de verilmiştir.

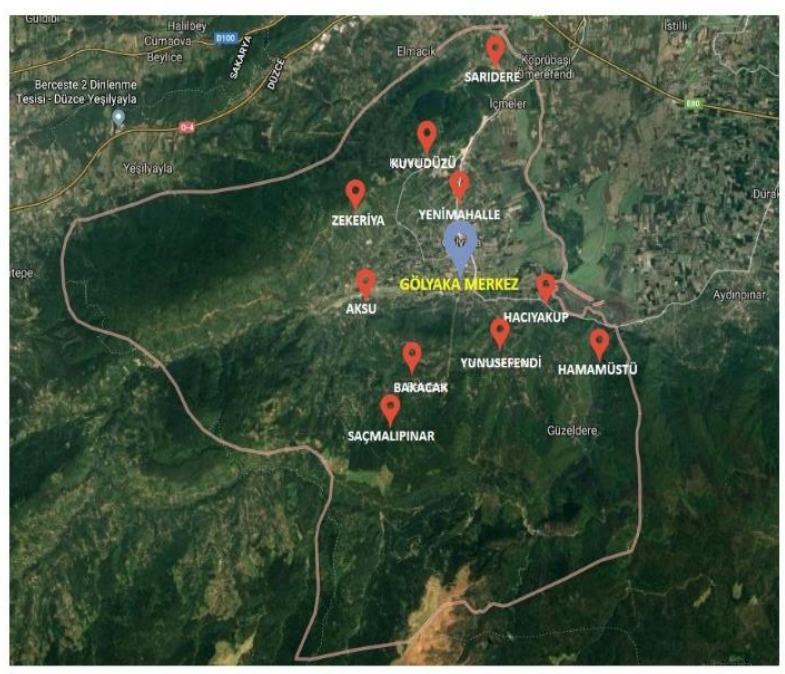

Şekil 1. Gölyaka'da arazi çalışmalarının gerçekleştirildiği köylerin ilçe haritasındaki yerleri.

Çalışma bölgesinde kaynak kişi olarak, belirlenen köylerde yaşayan farklı yaştaki (20-90 yaş) 114 kişi ile görüşme yapılmıştır. Kaynak kişilerin kullandıkları bitkiler ile ilgili bilgi toplanırken bitkinin yöresel ismi kayıt edildikten sonra bitki örnekleri kaynak kişi ile birlikte araziye çıkılarak bitkilerin doğal yetişme alanından toplanılmıştır. Ayrıca daha önce evinde var olup kuruttuğu ve sakladıkları bitkiler de varsa onlardan da örnekler alınmıştır. Toplanan bitki örnekleri herbaryum tekniğine göre kurutularak Düzce Üniversitesi Orman Fakültesi Herbaryumu'nda korunmaktadır. Kültür bitkilerinin herbaryum örnekleri hazırlanmamıştır. Toplanan bitkilerin teşhisinde kaynak 
olarak P.H Davis'in "Flora of Turkey and the East Agean Islands" adlı eserlerinden faydalanılmıştır (Davis, 1965-1985). Bilimsel isimlerin güncel durumları The Plantlist web sitesinden kontrol edilerek düzeltilmiştir (www.theplantlist.org).

\section{Bulgular}

Gölyaka ilçesine ait olan köylerde yapılan çalışma sonucunda yöre halkı tarafından çeşitli amaçlarla geleneksel kullanıma sahip olan bitkilerin yöresel isimleri Çizelge 1'de bitkilerin bilimsel isimlerine göre alfabetik düzende sunulmuştur. Bitkilerin familyaları bilimsel isminden sonra parantez içinde yazılmıştır. 114 kaynak kişi ile görüşme sonucunda bilimsel teşhisleri tamamlanan 114 taksona ait toplam 189 yöresel isim kayıt edilmiştir. Yöresel bitki isimleri kaynak kişilerden kayıt edilirken telaffuz farklılığ1 göz önüne alınmış ve listede her biri ayrı bir isim olarak yazılmıştır.

Çizelge 1. Araştırma sonucu Gölyaka ilçesi çevresinde tespit edilen bitki ve mantarların yöresel isimleri.

\begin{tabular}{|c|c|}
\hline Bilimsel İsim & Yöresel İsim \\
\hline Alcea apterocarpa (Fenzl) Boiss & Fatma ana, Gül hatmi \\
\hline *Allium porrum L. (Liliaceae) & Pirasa \\
\hline Alnus glutinosa (L.) Gaertn. (Betulaceae) & Kızılağaç \\
\hline Alopecurus myosuroides Huds. (Poaceae) & Tilki kuyruğu \\
\hline Amaranthus bybridus L. (Amaranthaceae) & Ciclega, Hoşgıran, Hoşkıran, Karahoşkıran \\
\hline *Anethum graveolens L. (Apiaceae) & Dere otu \\
\hline Anthemis cotula L. (Asteraceae) & May1s papatyas1 \\
\hline Arum orientale M. Bieb. (Araceae) & Yilan otu, Yılan yastığ \\
\hline${ }^{*}$ Avena sativa $\mathrm{L}$. (Poaceae) & Yulaf \\
\hline Bellis perennis L. (Asteraceae) & Papatya \\
\hline *Beta vulgaris L. (Amaranthaceae) & Çükündür, Kırmızı pancar, Pezük \\
\hline${ }^{*}$ Brassica oleracea L. (Brassicaceae) & Beyaz lahana \\
\hline *Brassica oleracea L. var. acephala DC. (Brassicaceae) & Karalahana \\
\hline Calystegia sepium (L.) R. Br. (Convolvulaceae) & Bürük otu, Sarmaşık, Tarla sarmaşığı \\
\hline${ }^{*}$ Capsicum annum L. (Solanaceae) & Kırmızı biber \\
\hline Carpinus betulus L. (Betulaceae) & Gürgen \\
\hline Castanea sativa Mill. (Fagaceae) & Kestane \\
\hline Chaerophyllum byzantinum Boiss. (Apiaceae) & Baldıran otu, Mendek otu \\
\hline Chelidonium majus L. ( Papaveraceae) & Kırlangıç kuyruğu, Kırlangı̣ç otu \\
\hline Chondrilla juncea L. (Asteraceae) & Sakız otu \\
\hline Cichorium intybus L. (Asteraceae) & Hindibağ \\
\hline Cirsium vulgare L. (Asteraceae) & Deve dikeni, Eşek dikeni \\
\hline $\begin{array}{l}\text { *Citrullus lanatus (Thunb.) Matsum. \& Nakai } \\
\text { (Cucurbitaceae) }\end{array}$ & Bostan, Karpuz \\
\hline${ }^{*}$ Coriandrum sativum L. (Apiaceae) & Ahusho, Kinzi, Kişniş \\
\hline
\end{tabular}


Çizelge 1'in devamı

\begin{tabular}{|c|c|}
\hline Bilimsel İsim & Yöresel İsim \\
\hline Cornus mas L. (Cornaceae) & Kizilcik \\
\hline${ }^{*}$ Corylus avellana L. (Betulaceae) & Findik \\
\hline Cota tinctoria (L.) J. Gay. (Asteraceae) & Boyac1 papatyas1, Papatya \\
\hline${ }^{*}$ Cucurbita maxima Duchesne (Cucurbitaceae) & Bal kabağ1, Kara kabak \\
\hline${ }^{*}$ Cucurbita moschata Duchesne (Cucurbitaceae) & Ak kabak, Balkabağı, Beyaz kabak, Kabak \\
\hline${ }^{*}$ Cydonia oblonga Mill. (Rosaceae) & Ayva \\
\hline Diospyros lotus L. (Ebenaceae) & Yabani hurma \\
\hline Dorycnium graecum (L.) Ser. (Fabaceae) & Yabani yonca, Yonca \\
\hline Echium vulgare L. (Boraginaceae) & Engerek otu, Yara otu \\
\hline Equisetum arvense L. (Equisetaceae) & At kuyruğu, Çam otu, Kilit otu, Şeytanı çamı \\
\hline Eruca vesicaria (L.) Cav (Brassicaceae) & Roka \\
\hline Euphorbia helioscopia L. (Euphorbiaceae) & Sütleğen \\
\hline Fagus orientalis Lipsky (Fagaceae) & Kayin \\
\hline Ficaria verna Huds. (Ranunculaceae) & Düğün çiçeği, Horoz otu \\
\hline *Ficus carica L. (Moraceae) & İncir \\
\hline${ }^{*}$ Fragaria vesca L. (Rosaceae) & Dağ çileği \\
\hline Galega officinalis L. (Fabaceae) & Ar1 otu, Fi ̌̆ \\
\hline *Helianthus tuberosus L. (Asteraceae) & Yer elmasi \\
\hline Helleborus orientalis Lam. (Ranunculaceae) & Bohça otu, Çöpleme \\
\hline Heracleum platytaenium Boiss. (Apiaceae) & Ezelte \\
\hline${ }^{*}$ Hydrangea macropbylla (Thunb.) Ser. (Brassicaceae) & Ortanca \\
\hline Hypericum calycinum L. (Hypericaceae) & Kılıç otu \\
\hline Hypericum perforatum L. (Hypericaceae) & Sarl kantaron \\
\hline *Juglans regia L. (Juglandaceae) & Ceviz \\
\hline Lamium purpureum L. (Lamiaceae) & Ballibaba \\
\hline Lapsana communis L. (Asteraceae) & Sütlü ot \\
\hline${ }^{*}$ Laurus nobilis L. (Lauraceae) & Defne \\
\hline Leucanthemum vulgare (Vaill.) Lam. (Asteraceae) & Süs papatyas 1 \\
\hline Lysimachia punctata L. (Primulaceae) & Karga otu \\
\hline${ }^{*}$ Malus sylvestris (L.) Mill. (Rosaceae) & Elma \\
\hline Malva nicaeensis All. (Malvaceae) & Boloşe, Ebegümeci, Ebelik, Höngül \\
\hline Medicago arabica (L.) Huds. (Fabaceae) & Yonca \\
\hline Medicago minima (L.) L. (Fabaceae) & Yonca \\
\hline Melissa officinalis L. (Lamiaceae) & Arhana, Rahana, Reyhan \\
\hline $\begin{array}{l}\text { Mentha longifolia (L.) L. subsp. typhoides (Briq.) Harley. } \\
\text { (Lamiaceae) }\end{array}$ & Yabani nane \\
\hline Mentha piperita L. (Lamiaceae) & Nane \\
\hline Mespilus germanica L. (Rosaceae) & Muşmula, Töngel \\
\hline
\end{tabular}


Çizelge 1'in devamı

\begin{tabular}{|c|c|}
\hline Bilimsel İsim & Yöresel İsim \\
\hline${ }^{*}$ Mirabilis jalapa L. (Nyctaginaceae) & Akşam sefas1 \\
\hline${ }^{*}$ Morus alba L. (Moraceae) & Beyaz dut, Dut \\
\hline Oenanthe pimpinelloides L. (Apiaceae) & Kaz ayağı, Sirken \\
\hline Petasites bybridus (L.) (Asteraceae) & Kabalak, Öksürük otu \\
\hline *Petroselinum crispum (Mill.) Fuss (Apiaceae) & Maydanoz \\
\hline *Phaseolus vulgaris L. (Fabaceae) & Fasülye \\
\hline Phytolacca americana L. (Phytolaccaceae) & Şekerci boyası, Zikkım otu \\
\hline *Pinus sylvestris L. (Pinaceae) & Çam \\
\hline *Pisum sativum L. (Fabaceae) & Bezelye \\
\hline Plantago lanceolata L. (Plantaginaceae) & Yilan dili \\
\hline Plantago major L. (Plantaginaceae) & Damar otu, Damarlı ot, Sinir otu \\
\hline Platanus orientalis L. (Platanaceae) & Çınar, Kavran \\
\hline *Populus alba L. (Salicaceae) & Kavak \\
\hline *Portulaca oleracea L. (Portulaceae) & Semiz otu \\
\hline Potentilla reptans L. (Rosaceae) & Beş parmak otu \\
\hline Primula vulgaris Huds.(Primulaceae) & Yabani menekşe \\
\hline *Prunus avium (L.) Moench (Rosaceae) & Beyaz kiraz, Kiraz \\
\hline *Prunus cerasifera Ehrh. (Rosaceae) & Erik \\
\hline *Prunus cerasus L. (Rosaceae) & Vişne \\
\hline Prunus laurocerasus L. (Rosaceae) & Karayemiş, Laz üzümü, Taflan \\
\hline${ }^{*}$ Pyrus communis L. (Rosaceae) & Armut \\
\hline Ribes rubrum L. (Grossulariaceae) & Kuş üzümü \\
\hline Robinia psendoacacia L. (Fabaceae) & Akasya \\
\hline Rosa canina L. (Rosaceae) & Kuşburnu \\
\hline${ }^{*}$ Rosmarinus officinalis L. (Lamiaceae) & Biberiye \\
\hline Rubus discolor Weihe \& Nees (Rosaceae) & Böğürtlen, Böğürtleyen \\
\hline Rubus birtus Waldst. \& Kit. (Rosaceae) & Böğürtlen, Böğürtleyen \\
\hline Rumex conglomeratus Murray (Polygonaceae) & Ebelik otu, Efelek, Evelek, Labada \\
\hline Salix babylonica L. (Salicaceae) & Salkım söğüt \\
\hline Salvia forskablei L. (Lamiaceae) & Ballı ot, Bannık \\
\hline *Salvia tomentosa Mill. (Lamiaceae) & Adaçayı \\
\hline Sambucus ebulus L. (Adoxaceae) & Yer mürveri, Yidin, Yiğidin, Yiğidin otu, Yiyidin \\
\hline Satureja hortensis L. (Lamiaceae) & Azıbra \\
\hline Smilax excelsa L. (Smilacaceae) & Diken ucu, Kırçan otu \\
\hline *Solanum melongena L. (Solanacae) & Baldircan, Patlican \\
\hline Tanacetum parthenium (L.) Sch. Bip (Asteraceae) & Papatya \\
\hline Taraxacum laevigatum (Willd.) DC. (Asteraceae) & Karahindiba, Karahindibăg \\
\hline Thymus longicaulis C. Presl (Lamiaceae) & Asıbra, Azıbra, Kekik, Yabani kekik \\
\hline
\end{tabular}




\begin{tabular}{|c|c|}
\hline Bilimsel İsim & Yöresel İsim \\
\hline *Tilia tomentosa Moench (Malvaceae) & Ihlamur \\
\hline Trachystemon orientalis (L.) D. Don (Boraginaceae) & Galdırık, Hodan, Ispit, Kaldirek, Kaldirik, Tomaro \\
\hline Trifolium bybridum L. (Fabaceae) & Yonca \\
\hline Trifolium pratense L. (Fabaceae) & Ak üçgül, Üçgül, Yonca \\
\hline *Triticum durum Desf. (Poaceae) & Buğday \\
\hline Urtica dioica L. (Urticaceae) & Dalan, Isırgan, Isirgan otu \\
\hline${ }^{*}$ Vicia faba L. (Fabaceae) & Bakla \\
\hline Vinca major L. (Apocynaceae) & Menekşe \\
\hline Viscum album L. (Santalaceae) & Armut purçu, Çekem, Ökse otu \\
\hline${ }^{*}$ Vitis labrusca L. (Vitaceae) & Kara üzüm, Kokulu üzüm \\
\hline *Zea mays L. (Poaceae) & Dar1, Misır \\
\hline${ }^{*}$ Zinnia elegans L. (Asteraceae) & Kirli hanım çiçeği, Papatya \\
\hline *Zinnia angustifolia Kunth (Asteraceae) & Kirli hanım çiçeği, Papatya \\
\hline
\end{tabular}

\section{Sonuç ve Tartışma}

İnsanların bitkilerden faydalanabilmeleri için öncelikle onları adlandırmaları gerekmektedir. Farklı kültürlerdeki insanlar kendi çevresinde bulunan, yetiştirdiği ya da takas yoluyla sağladığı bitkileri kendi kültürüne göre kullanmakta ve adlandırmaktadır. İnsanlar çeşitli amaçlarla kullandıkları bu bitkilerin adlandırılmasında bitkilerin kullanım özelliklerini, renklerini, görünümlerini ve daha birçok özelliklerini dikkate almıştır (Alkayış, 2019). Çalışma bölgemizde kaynak kişiler ile yapılan görüşmeler sonucu teşhisi yapılan bitki adlarında da bu özellikler görülmüştür. Bu isimlendirmeler aşağıdaki şekilde gruplandırılmıştır.

Renk özelliğinden yararlanarak adlandırılan bitkiler; Beyaz dut, Beyaz kabak, Beyaz kiraz, Beyaz lahana, Karahindibağ, Karahoşkıran, Kara kabak, Karalahana, Kara üzüm, Kırmızı biber, Kırmızı pancar, Kızılağaç, Sarı kantaron,.

Belirgin bir özelliğine göre adlandırılan bitkiler; Arı otu ve Ballıbaba (arılar için nektar ihtiva eder), Isırgan (bitkinin içerdiği sıvı ciltte kaşıntı yapar), Diken ucu (bitkide dikenler yer alır), Sakız otu (gövdesi taze iken sakız gibi gri yapışkan bir madde içerir), Sütleğen (gövde ve dalları kırıldığında süt benzeri beyaz bir sıv1 ç1karır), Şekerci boyası (bitki bünyesinde boyar madde ihtiva eder).

İnsan ismine göre adlandırılan bitkiler; Fatma ana, Reyhan, Yiğidin.
Hayvan ismine göre adlandırılan bitkiler; At kuyruğu, Ar1 otu, Engerek otu, Deve dikeni, Eşek dikeni, Horoz otu, Karga otu, Kaz ayağı, Kırlangıç otu, Kırlangıç kuyruğu, Kuşburnu, Kuş üzümü, Tilki kuyruğu, Yılan dili, Yılan otu, Yılan yastığı.

Organ ismine göre adlandırılan bitkiler; At kuyruğu, Baldıran otu, Beş parmak otu, Çükündür, Damar otu, Kaz ayağı, Kırlangıç kuyruğu, Kuşburnu, Tilki kuyruğu, Yılan dili.

Nesne ismine göre adlandırılan bitkiler; Adaçayı, Armut purçu, Bürük otu, Deve dikeni, Diken ucu, Eşek dikeni, Kılıç otu, Kilit otu, Sakız otu, Salkım söğüt, Yılan yastığı.

Zehirli olma özelliğine göre adlandırılan bitkiler; Z1kkım otu.

Kullanım özelliklerine göre adlandırılan bitkiler; Arı otu (arılar bal yapımında kullanır), Şekerci boyası (yün boyamada kullanilır).

Yetişme ortamına göre adlandırılan bitkiler; Dere otu, Dağ çileği, Tarla sarmaşığı, Yer elması.

Doğallı̆̆1 dikkat çekerek adlandırılan bitkiler; Kültür bitkilerinden farklı olarak doğal ortamda yetişen bitkilere Yabani hurma, Yabani yonca, Yabani nane, Yabani menekşe, Dağ çileği isimleri verilmiştir. 
Yörede yapilan çalıșma sonucu elde edilen bulgularımız bölgede yakın il ve ilçelerde yapılan diğer etnobotanik çalışmalarla karşılaştırılarak da değerlendirilmiştir. $\mathrm{Bu}$ amaçla Düzce ili ve yakın çevresinde yapılan literatür çalışmalarına örnek olarak Koçyiğit (2005), Kızılarslan ve Özhatay (2009), Koyuncu ve ark. (2009), Doğru Koca ve Yildırımlı (2010), Bat1 (2018), Gürbüz ve ark. (2019) çalş̧maları değerlendirilmiştir.

Çalışmamızda Hypericum calycinum bitkisi "Kılıç otu" olarak adlandırılmıştır. Aynı bitki Yalova ilinde yapılan çalışmada "Saat çiçeği", "Sicim otu", "Yaban gülü" ve "Tavuk yumurtalamaz" isimleri ile adlandırılmıştır (Koçyiğit, 2005:60). Bu bitkinin İzmit Körfezi'nde yapılan çalş̧mada da "Güneşotu", "Geyikotu", "Koyunkıran", "Kamaniçaotu" isimleri ile adlandırıldığı görülmektedir (Kızılarslan ve Özhatay, 2009:42).

Düzce yöresinde Gürbüz ve ark. (2019)' da yaptığı bir çalışmada "Efelek", "Pazı" olarak bilinen Beta vulgaris türüne bu yöresel isimlerin yanında çalışma alanımız Gölyaka'da "Kırmızı pancar", "Pezük", "Çükündür" adının da verildiği ve aynı bitkinin değişik isimlerle de adlandırıldığı tespit edilmiştir. Çalışma bölgemizde Bellis perennis bitkisi yöre halk1 tarafından "Papatya" olarak adlandirlırken, Yalova ilinde yapilan çalışmada aynı bitki için "Koyungözü" ve "Nineotu" isimlerinin kullanıldığı görülmüştür (Koçyiğit, 2005:33). Cichorium intybus bitkisi çalışmamızda "Hindibağ" olarak isimlendirilirken Yalova ilinde yapıllan çalışmada "Sakız otu" ve "Sakızlık otu" olarak adlandırılmaktadır (Koçyiğit, 2005:36). Çalışmamızda Mespilus germanica bitkisi "Töngel", "Muşmula" isimleri ile adlandırılırken aynı bitki için Yalova ilinde yapılan çalışmada "Beşbıyık", "Döngel" "Oşhamuşk" gibi yöresel bazı isimlerin kullanıldığı görülmektedir (Koçyiğit, 2005:110). Bu bitki için kullanılan "Töngel" ve "Döngel" ismi yöresel olarak telaffuz farklılığı içeren bitkilere örnek olarak gösterilebilir.

Laurus nobilis bitkisi çalışmamızda "Defne" olarak adlandırılırken aynı bitki İzmit Körfezi yöresinde yapılan çalışmada farklı telaffuz biçimleri ile "Depne" ve "Define" olarak adlandırılmışır (Kızılarslan ve Özhatay, 2009).

Çalışmamızda Amaranthus hybridus olarak tespit edilen ve yörede "Ciclega", "Karahoşkıran”, "Hoşkıran”, "Hoşgrran" olarakta isimlendiren bitkinin Akçakoca (Düzce) ilçesinin florası ve etnobotanik özellikleri adlı çalş̧mada Amarantus lividus türününde yörede "Hoşguran" ve "Kızılca mancar" olarak benzer yöresel isimlerle bilindiği tespit edilmiştir (Doğru Koca ve Yıldııılı, 2010:64). Çalışma alanımız olan Gölyaka ilçesinde Rumex conglomeratus türü "Labada", "Efelek", "Evelek", "Ebelik otu" gibi isimlerle adlandirllırken, İzmit Körfezi yöresinde Rumex pulcher türüne de "Efelek", "Evelek", "Ebelik otu" gibi benzer yöresel isimler verildiği görülmektedir (Kızılarslan ve Özhatay, 2009:44). Çalışmamızda "At kuyruğu", "Çam otu”, "Kilit otu", "Şeytanı çamı" olarak adlandırılan Equisetum arvense türünün Düzce yöresinde Gürbüz ve ark. (2019)'da yaptığ bir başka çalışmada Equisetum telmateia türü ile aynı isimlerle adlandırıldığı dikkati çekmiştir.

Gölyaka ilçesinde Mentha longifolia subsp. typhoides türünün "Yabani nane" olarak isimlendirildiği, aynı bitkinin Düzce yöresinde yapılan farklı çalışmalarda "Anık otu", "Anuk" olarak adlandırıldığ1, Yalova ve Akçakoca da ise aynı türe "Eşek nanesi”, "Köpek nanesi” isimlerinin verildiği bildirilmiştir (Koçyiğit, 2005:67; Doğru Koca ve Yıldırıml, 2010:66; Gürbüz ve ark., 2019:26). Araştırma bölgesinde Aksu köyünde yaşayan halk tarafindan çok kullanılan Melissa officinalis türüne ait bitki "Reyhan", "Arhana" ve "Rahana" olarak adlandırılmıştır. Aynı bitki İzmit Körfezi yöresinde yapılan bir çalışmada "Oğulotu”, "Saçkıran", "Yabani dereotu", "Yaban 1sırganı" olarak adlandırılmıştır (Kızılarslan ve Özhatay, 2009:42). Çalışma bölgemizde tespiti yapilan Chaerophyllum byzantinum bitkisi yörede "Baldıran otu", "Mendek otu" gibi isimlerle adlandırılırken İzmit Körfezi’nde yapılan çalışmada aynı bitkiye "Yoğurtotu", "Çarşır", "Çarşırotu” gibi isimlerin verildiği görülmektedir (Kuzılarslan ve Özhatay, 2009:40).

Çalışmamızda Hypericum perforatum olarak tespit edilen ve yörede "Sar kantaron" olarak isimlendiren bitkinin Sakarya (Geyve)'de yapılan çalışmada "Kantaron", "Mayasil otu", "Yara otu" olarak adlandırıldığı tespit edilirken, Bilecik yöresinde yapılan çalışmada "Binbirdelikotu", İzmit Körfezi çevresinde yapılan çalışmada da "Kanterçiçeği" ve "Kantaron" adını aldığ1 görülmüştür (Kızılarslan ve Özhatay, 2009:42; Koyuncu ve ark., 2009:129; Bat1, 2018:103).

Araştırma bölgesindeki kaynak kişilerce " $\mathrm{Kaz}$ ayă̆g" ismi ile adlandırılan Oenanthe pimpinelloides türünün İzmit Körfezi'nde yapılan çalışmada aynı ismin dışında "Kazayak", "Kazyağı", "Kazıyak", "Kazbacağı", "Yabani maydanoz", "Kazyakotu” gibi değişik isimlerle adlandırıldığ tespit edilmiş, bu bitkiye Akçakoca bölgesinde de "Kişkiş otu", "Kalçak mancarı" gibi farklı adların verildiği kaydedilmiştir (Kızılarslan ve Özhatay, 2009:43; Doğru Koca ve Yıldırımlı, 2010:66). Gölyaka yöresinde "Diken ucu", "Kırçan otu" olarak adlandırılan Smilax excelsa türü Düzce ilinde yapilan diğer bir çalışmada "Burçman", "Diken ucu", "Gıcır dikeni”", "Karasal dikeni", "Melovcan", "Meloncan dikeni", "Melican", "Meravcan" isimleri ile bilinmektedir 
(Gürbüz ve ark., 2019:54). Bu bitkinin İzmit Körfezi yöresinde "Gıcırdakdikeni”, "Kușevin", "Zimilaçidikeni", Yalova ilinde "Gıcır" ve Akçakoca'da "Melülcan" ve "Kuş mancarı", Sakarya (Geyve) yöresinde "Zimilaci”, "Zimilaçi”, "Zimbilaçi”, "Özbek dikeni", "Melevcen" gibi isimlerle adlandırıldığ1 görülmüş̧ür (Koçyiğit, 2005:145; Kızılarslan ve Özhatay, 2009:44; Koyuncu ve ark., 2009:133; Doğru Koca ve Yildırıml, 2010:66).

Çalışmamızda Rosa canina bilimsel ismi ile adlandırılan ve genelde yaygın olarak "Kuşburnu" olarak da bilinen bitkinin Sakarya (Geyve) ve Bilecik yöresinde yapilan çalışmalarda "Yaban gülü", Yalova çevresinde yapılan çalışmada "Köpek gülü", İzmit Körfezi çevresinde yapılan çalışmada ise "Dikenbaşı", "Öküzgötü”, "Köpekgülü", "Yabanigül”, Düzce yöresinde yapılan diğer bir çalışmada da aynı bitki için "Gül tomurcuğu", "İtburnu", "Kuşburnu", "Köpekdikeni”, "Yabangülü" adlandırlmalarının yapıldığ1 görülmüsstür (Koçyiğit, 2005:112; Kızılarslan ve Özhatay, 2009:44; Koyuncu ve ark., 2009:127; Bat1, 2018:99; Gürbüz ve ark., 2019:28).

Çalışmamızda Trachystemon orientalis bilimsel ismi ile bilinen ve bölgede çok yaygın kullanımı olan "Kaldirik", "Kaldirek", "Galdırık", "Hodan", "Ispit" ve "Tomaro" isimleri ile bilinen bitki, Yalova yöresinde yapılan bir çalışmada "Zılbırt" olarak adlandırılmışır (Koçyiğit, 2005:24).

Çalışma bölgemizde hemen hemen her yerde yetişen ve yörede çok iyi bilinen Sambucus ebulus türü için "Yiğidin", "Yidin", "Yiyidin" isminin yanında Düzce ve Akçakoca yöresinde "Gülüzotu", "Gülüz”, "Nivirdin”, "Nivürden”, "Onjura", "Öküz Kuyruğu”, "Sultanotu” ve "Şahmelik" gibi adlandırmaların da olduğu görülmüştür (Doğru Koca ve Yıldırımlı, 2010:65; Gürbüz ve ark., 2019:51). Yalova ilinde yapıllan çalışmada bu bitkinin "Sultanotu" ve "Piramuj" isimleri ile adlandırıldığı kaydedilmiştir (Koçyiğit, 2005:26). İzmit Körfezi çevresinde yapilan çalışmada ise bu bitki için "Şahmelekotu", "Şahmelek", "Sultan", "Piran", "Lüver" ve "Lor" gibi farklı adlandırmaların olduğu görülmüştür (Kızılarslan ve Özhatay, 2009:44).

$$
\text { Yapılan arazi çalışmalarında bitki }
$$
adlandırılmasında yöre halkının aynı cinsin farklı türlerine de aynı ismi verdiği görülmüştür. Zinnia elegans ve Zinnia angustifolia türlerinin ikisine birden "Papatya" denildiği tespit edilirken, Medicago arabica, Medicago minima, Dorycnium graecum, Trifolium bybridum, Trifolium pratense gibi aynı familyanın farklı türlerine "Yonca" isminin verildiği kaydedilmiştir.
Elde edilen bilgiler ıșığında çalışma alanımıza yakın bölgelerde yapılan diğer çalışmalarda tespit edilen taksonların bölgede yaşayan halk tarafindan aynı tür için farklı isimlerle adlandırıldığ belirlenmiştir. Çalışmada göze çarpan diğer bir noktada karşlaşıırma yapılan diğer yörelerde bazı taksonlar için ortak adlandırmanın yapıldığıdır. Gürbüz ve ark. (2019)'da yapmış olduğu çalısmada Rosa canina türü için "Kuşburnu", Smilax excelsa türü için "Diken ucu" isimlerinin yapilan çalışmada tespiti yapılan aynı türlerde de ortak isim olarak kullanıldığı tespit edilmiştir. Çalışma bölgesinde belirlenen taksonların yöre halk1 tarafindan adlandırılmasında bu bitkilerin kullanımının yanında renk, biçim ve görünümünün dikkate alındığı, bitkilerin geleneksel adlandirlmasinda en yaygin kullanilan yaklaşımın renk özelliklerinden yararlanılarak olduğu belirlenmiştir. Çalışma sonucunda Gölyaka (Düzce) ilçesinin bitki çeşitliliği ve bu bitkilerden yararlanma konusunda zengin bir birikime sahip olduğu görülmüştür.

\section{Kaynaklar}

Aksoy N., Özkan N. G., Aslan S., Koçer N., 2015. Düzce ili bitki biyolojik çeşitliliği, endemik, nadir bitkiler taksonlar1 ve koruma statüleri. II. Uluslararası Düzce Tarih, Kültür ve Sanat Semposyumu, Aralik, 409-421.

Alkayış, M. F., 2019. Türkiye Türkçesinde bitki adlar. Hiperlink Yayınları, İstanbul.

Altundağ E., Özhatay N., 2009. Local names of some useful plants from Igdir province (East Anatolia). İstanbul Journal of Pharmacy, 40:101 -115.

Batı C., 2018. Abbaslık Köyü (Bilecik) florası ve etnobotanik özellikleri. Hacettepe Üniversitesi, Fen Bilimleri Enstituisü, Biyoloji Anabilim Dal, Yülesek Lisans Tezi, 137 sayfa.

Baytop A., 2007. Türkse bitki adlar sǫ̈lügü. Türk Dil Kurumu Yayınlar, Üçüncü Baskı, Ankara.

Davis P. H., 1965-1985. Flora of Turkey and the East Aegean Islands. 1-9, Edinburgh: Edinburgh University Press.

Dikilitaş B., Güler B., Uğurlu E., Altan Y., 2016. Ovacık (Karabük) ve çevresinin floristik özellikleri. Celal Bayar Üniversitesi Fen Bilimleri Dergisi, 12(2):253-264.

Doğru Koca A., Yıldırımlı Ş., 2010. Ethnobotanical properties of Akçakoca district in Düzce (Turkey). Hacettepe Journal of Biology and Chemistry, 38(1):63-69. 
Ertuğ F., 2004. Etnobotanik çalışmalanı ve Türkiye'de yeni açlilimlar. Kebikeç Dergisi, 18:181-187.

Gürbüz İ., Gençler Özkan A. M., Akaydın G., Salihoğlu E., Günbatan T., Demirci F., Yeşilada E., 2019. Folk medicine in Düzce province (Turkey). Turkish Journal of Botany, 43(6).

Kızılarslan C.., Özhatay N., 2009. Local names of some plants from the south part of Izmit (Northwest Turkey), Istanbul Journal of Pharmacy, 40:37-46.

Koçyiğit M., 2005. Yalova ilinde etnobotanik bir araştırma, İstanbul Üniversitesi Sağllk Bilimleri Enstitüsü, Farmasötik Botanik Anabilim Dal, Yüksek Lisans Tezi, 176 sayfa.

Koyuncu O., Yaylacı Ö. K., Tokur S., 2009. A study on Geyve (Sakarya) and its environs in terms of ethnobotanical aspects, OT Sistematik Botanik Dergisi, 16(1):123-142.

Sevgi E. , Kızılarslan Hançer Ç., Akkaya M, Altundağ Çakır E., 2018. Biga'da (Çanakkale) geleneksel kullanımı olan bitkilerin yöresel adları ve adlandırma yaklaşımları. Avrasya Terim Dergisi, 6(1):35-47.

The Plantlist, 2020. http://www.theplantlist.org (Ziyaret tarihi: $10 / 03 / 2020$ )

Yeşil Y., Akalın E., 2010. The use of wild edible plants in kürecik (Akcadag/Malatya). Istanbul Journal of Pharmacy, 41: 90-103.

Yıldırımlı S., 2004. Etnobotanik ve Türk Etnobotaniği. Kebikeç Dergisi, 17: 175-193. 